\title{
RETRACTED ARTICLE: Direct healthcare costs of spinal disorders in Brazil
}

\author{
Rodrigo Luiz Carregaro $^{1,2}$ (D) Everton Nunes da Silva ${ }^{3}$ (D) Maurits van Tulder ${ }^{2}$ (D)
}

Received: 26 March 2018 / Accepted: 5 April 2018/Published online: 12 April 2018

(c) The Author(s) 2018

This article has been retracted as it was inadvertently moved to production before final acceptance, the Journal and the Publisher apologise for this error. The authors have been given the opportunity to resubmit the manuscript to the Journal to complete the peer review process. The authors agree to this retraction. The online version of this article contains the full text of the retracted article as electronic supplementary material.
Open Access This article is distributed under the terms of the Creative Commons Attribution 4.0 International License (http://creative commons.org/licenses/by/4.0/), which permits unrestricted use, distribution, and reproduction in any medium, provided you give appropriate credit to the original author(s) and the source, provide a link to the Creative Commons license, and indicate if changes were made.

Electronic supplementary material The online version of this article (https://doi.org/10.1007/s00038-018-1099-1) contains supplementary material, which is available to authorized users.

Rodrigo Luiz Carregaro

rodrigocarregaro@unb.br

1 School of Physical Therapy, Universidade de Brasília (UnB), Campus UnB Ceilândia, Centro Metropolitano, conjunto A, lote 01, Brasília, DF CEP 72220-275, Brazil

2 Department of Health Sciences, Faculty of Science, Vrije Universiteit Amsterdam, Amsterdam, The Netherlands

3 School of Collective Health, Universidade de Brasília (UnB), Campus UnB Ceilândia, Brasília, Brazil 